\title{
Married women's experience of domestic violence in Malawi: new evidence from a cluster and multinominal logistic regression analysis
}

\section{Lana Chikhungu, Mark Lyons-Amos, Ngianga li Kandala, Sasee Pallikadavath}

\begin{abstract}
:
Background: Violence against women is a global issue with estimates indicating that $35 \%$ of all women world-wide have experienced either physical and/or sexual intimate partner violence or non-partner violence in their life time. In Malawi $42 \%$ of ever-married women have experienced some form of violence perpetrated by their current or most recent spouse. A number of studies have investigated intimate partner violence in Malawi within the context of HIV/AIDS, girls' sexual abuse, psychological distress and a few report on the role of sociocultural factors in influencing gender based violence. No study has used cluster analysis to systematically analyse different levels of abuse amongst married women in Malawi.
\end{abstract}

Methods: Using the 2015 Malawi Demographic and Health Survey data, we employed cluster analysis and multinomial logistic regression to analyse the distribution of different levels of abuse amongst married women in Malawi and the key attributes associated with each level of abuse.

Results: Correlates of domestic violence significantly differ by levels of abuse and are distributed as follows; controlling behaviour (11.8\%), general controlling behaviour $(27.1 \%)$, moderate physical and emotional abuse (27.2\%) and the high and complete abuse (8.5\%). Alcohol consumption, ethnicity and women working status were significantly associated with all four levels of abuse but age and religion were only associated with controlling behaviour and generalised controlling behaviour. The strength of association between husband's alcohol consumption, woman's working status and marriage type and domestic violence increased by level of abuse. On each of these factors, the odds of experiencing violence were lowest in the controlling behaviour group and highest in the high physical and emotional abuse group.

Policy Recommendations: Policies and programmes that are designed to tackle violence 
against married women in Malawi should incorporate strategies that discourage excessive drinking, promote messages that women can be bread winners and discourage polygamous marriage.

\section{Introduction}

The WHO estimates that $35 \%$ of all women world-wide have experienced either physical and/or sexual intimate partner violence or non-partner violence in their life time (WHO, 2017). As many as $19 \%$ of women in 87 countries surveyed between 2005 and 2016 globally reported experiencing physical and sexual violence in the 12 months prior to the survey (United-Nations, 2018). In Malawi, the prevalence of domestic violence amongst the evermarried women perpetrated by their current or most recent spouse (physical, sexual or emotional) is estimated at $42 \%$, higher than the global estimate of intimate partner violence (NSO-Malawi \& DHS-Program, 2017). Sustainable development goal number 5 aims to achieve gender equality and empower all women and girls through various ways including the elimination of all forms of violence against all women and girls in the public and private spheres including trafficking and sexual and other types of exploitation(United-Nations, 2018). Efforts to tackle the problem of violence against women globally through advocacy, empowerment, counselling interventions and home visitation appear promising in general but not many countries have made significant strides in reducing violence against women(WHO, 2017). In Malawi there is concordance between men and women in their perception that women do not have the right to refuse sex whenever their husbands demand so and it is established that acceptance of intimate partner violence is both a barrier to its reduction and a strong predictor of prevalence (Andersson et al., 2007; Kaminaga, 2017).

There are many theories designed to explain, predict and better understand the causes of domestic violence. The feminist theory is considered a dominant model because it can be applied across cultures, contains both an explanation and a solution and emanates from the discipline of sociology with many feminist scholars(Gelles, 2005). It postulates that violence against women is a result of the inferior position occupied by women in the social structure inherited from a traditional family system and that marital violence emanates from inequalities that exist in marriage relationships(Renzetti et al., 2001). Feminists conceptualise all violence as a reflection of the unequal power relationships that exist in society and personal relationships between men and women(Sharma, 1997). However, a more thorough understanding of factors that influence domestic violence can be achieved by using 
the ecological framework (Figure 1). Carlson(1984) adapted Urie Bronfenbrenner's ecological model of human development to the problem of domestic violence. The ecological model of domestic violence allows for an analysis of factors at different levels; individual, family, community, society which may operate simultaneously, independently and interactively to influence the emanation and persistence of domestic violence. The WHO Violence Prevention Alliance uses the ecological framework to guide its understanding, undertake research and implement actions for violence prevention(WHO, 2018). This framework illustrates the factors that may influence violence at society and community level, within relationships and what makes individuals become perpetrators of domestic violence.

\section{Figure 1: The ecological framework: examples of risk factors at each level}

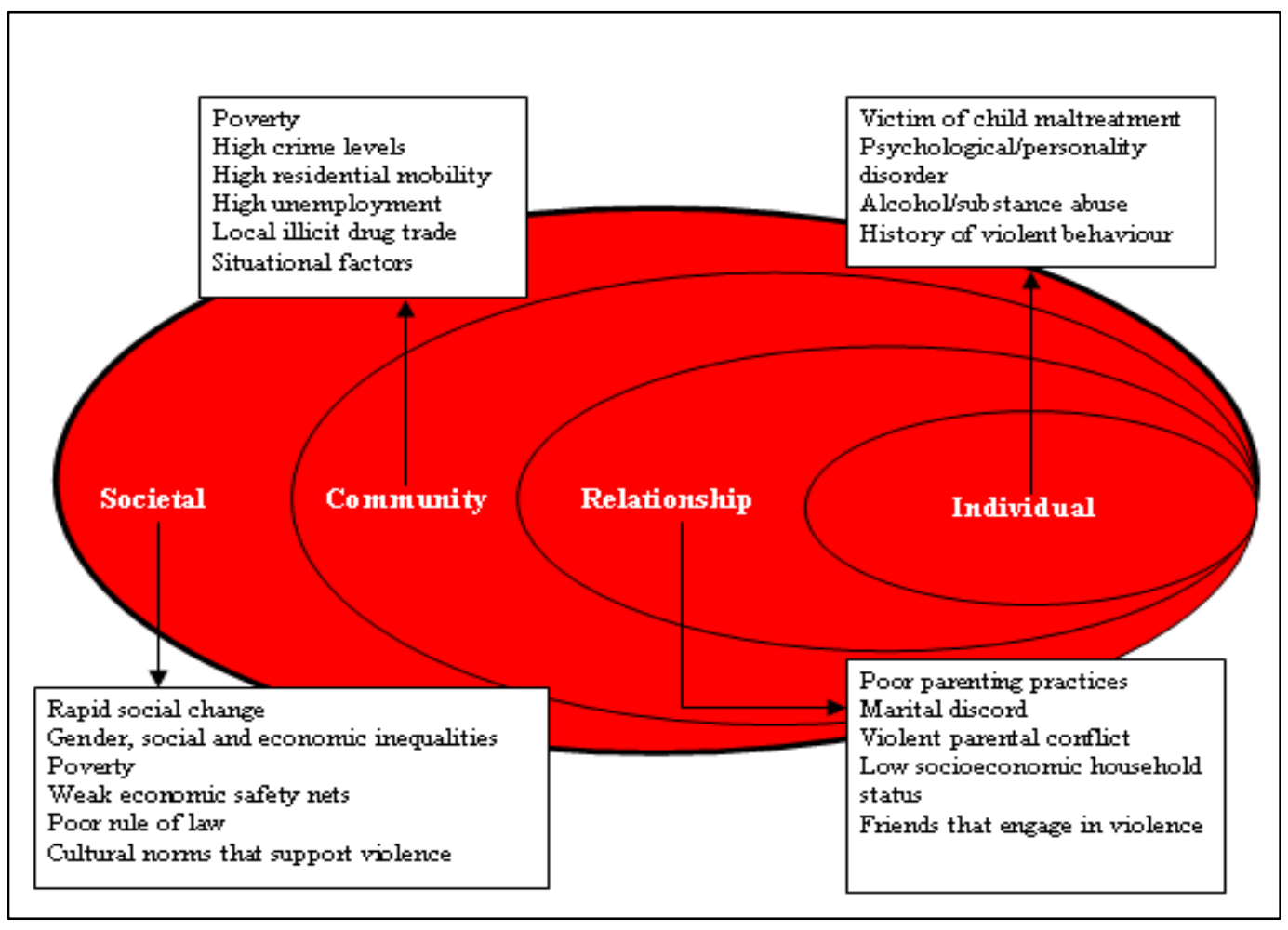

Source: WHO(2018) The VPA approach

http://www.who.int/violenceprevention/approach/ecology/en/

The interplay of factors shown in the ecological framework has attracted a significant amount of research on domestic violence across the globe. The evidence indicates that although in general the findings are aligned to the ecological framework, there are variations in the relative importance of factors responsible for domestic violence which may be attributed to differences in context, data and research methods. A number of studies have established that 
the risk of abuse is highest amongst women that are poor and unemployed which may linked to the resource theory, dependency relations theory, patriarchy theory and feminist theory (Dobash \& Dobash, 1979; Gelles, 2005; Hyde-Nolan \& Juliao, 2011; Jewkes, 2002; Strauss et al., 1980; Warner et al., 1986). The resource theory presupposes that family members with more resources traditionally command higher power and assure obedience and compliance while those with less resources use violence to maintain power(K. L. Anderson, 1997; Pallikadavath \& Bradley, 2018; Warner et al., 1986).

The dependency relations theory proposes that victims of abuse are often dependent on their abuser while patriarchy theory explains that the economic and social processes that operate directly and indirectly to support the patriarchal order lead to the subordination of and violence against women(Alio et al., 2011; Dobash \& Dobash, 1979; Hyde-Nolan \& Juliao, 2011; NSO-Malawi \& DHS-Program, 2017). Interestingly a cross-sectional household survey in eight countries found that poverty, overcrowding and education were less influential than socio-cultural factors such as multiple partners, attitudes and subjective norms(Andersson et al., 2007). Key socio-cultural factors associated with domestic violence in Malawi include forced marriage, dowry practice, polygyny and the notion of household head(Bisika, 2008). The presence of co-wife has been linked to domestic violence in several African countries including Malawi (Alio et al., 2011; Bisika, 2008). Although polygyny is common across all ethnicities in Malawi, it is more predominant amongst patrilineal communities in the Northern region. The Central and Southern regions are largely matrilineal(Berge et al., 2013; Chikhungu et al., 2014). Women from matrilineal communities are more autonomous which increases divorce rates(Arnado, 2004). It is not surprising that the Southern region of Malawi has a relatively larger percentage of female headed households (28\%) compared to the Central region(21.2\%) and the Northern region (19.9\%)(NSO-Malawi, 2012). Although most ethnicities follow one lineage system (matrilineal or patrilineal) some ethnic groupings e.g. the Ngonis and Nyanjas may be both matrilineal and patrilineal depending on their ancestral settlement area when they first migrated into Malawi(Berge et al., 2013; Telalagić, 2012).

At the global level, researchers have used multivariate analysis to explore factors associated with domestic violence amongst married women either in general or using one specific measure (physical, or emotional or sexual), and in some cases researchers have only undertaken bivariate analysis without controlling for other factors(Alio et al., 2011; Andersson et al., 2007; Fageeh, 2014; Rasoulian et al., 2014; Sapkota et al., 2016). Based on 
a literature review on gender based violence to inform national response in Malawi, a number of studies have investigated intimate partner violence within the context of HIV/AIDS and girls sexual abuse and a few have studied the role of socio-cultural factors in influencing gender based violence(Mellish et al., 2015). A recent Malawi national level study amongst 13 to 24 year olds established that psychological distress may result from experiencing multiple forms of domestic violence (Fan et al., 2017). No study has analysed the factors associated with the different levels of abuse in Malawi amongst married women. Using cluster analysis and multinomial logistic regression and national level data, this study identifies the distribution of different levels of abuse amongst married women in Malawi and the key attributes associated with each level of abuse. The study is exploratory in nature and uses the ecological framework and previous empirical work to inform variables of analysis. Study findings provide key information to help government and donor institutions make wellinformed policy decisions in tackling violence against women in Malawi and populations of similar attributes.

\section{Methods}

\section{Data}

The data are drawn from the 2015 Malawi Demographic and Health Survey (2015 MDHS) carried out under the DHS programme. The USAID funds the DHS programme in many developing countries. In the 2015 MDHS, ICF International provided technical assistance throughout the study. The sample was selected based on the 2008 Malawi Population and Housing Census frame. Standard enumeration areas were selected based on probability proportional to size. Thirty households were picked from each enumeration area to make a sample size of 27,516 households. The woman's questionnaire collected information from 24,562 women out of 25,146 women aged 15 to 49 years that were eligible for the interview representing a $98 \%$ response rate. One third of the sampled households received domestic violence questions (6,379 household). Specifically constructed weights were used to adjust for selection of only one woman per household to ensure national representativeness. Weights are therefore specific to the individual woman and are included in the analysis to make the sample nationally representative. The domestic violence module collected data on different types of violence; physical, sexual, emotional and level of marital control by husband. The survey also provided information on background characteristics including household wealth status and demographic characteristics of all household members such as age, sex and relationship to 
household head. Further details of study design and data collection are reported on the National Statistical Office of Malawi website: http://www.nsomalawi.mw/.

\section{Description of Variables}

\section{Explanatory Variables}

The choice of explanatory variables is guided by findings from previous literature, the ecological framework (figure 1) and data availability. The explanatory variables that were explored are described in Table 1. This comprises of demographic variables: age of the woman, age of the woman at first sex, age at first cohabitation, geographic/location variables: urban/rural residence, region, religion, ethnicity and socio-economic variables: household wealth status, whether husband takes alcohol or not, woman's education level, whether the woman is currently working or not and type of marriage (polygynous or monogamous)). 
Table 1 Distribution of variables explored in this study

\begin{tabular}{|c|c|c|c|}
\hline Demographic factors & Variable & Frequency & Percentage \\
\hline \multirow[t]{4}{*}{ Age } & $15-19$ & 353 & 7.69 \\
\hline & $20-29$ & 2,118 & 46.15 \\
\hline & $30-39$ & 1,461 & 31.84 \\
\hline & $40-49$ & 657 & 14.32 \\
\hline \multirow{6}{*}{ Age at first cohabitation/marriage } & Less than 13 years & 386 & 8.39 \\
\hline & 14 to 17 years & 2,658 & 57.92 \\
\hline & 18 years or over & 1,546 & 33.69 \\
\hline & Less than 15 years & 540 & 11.77 \\
\hline & 15 to 17 years & 1,819 & 39.64 \\
\hline & 18 years or more & 2,230 & 48.59 \\
\hline \multicolumn{4}{|l|}{ Geographical location } \\
\hline \multirow[t]{2}{*}{ Urban/rural residence } & Urban & 831 & 18.11 \\
\hline & Rural & 3,758 & 81.89 \\
\hline \multirow[t]{3}{*}{ Region } & Northern & 860 & 18.74 \\
\hline & Central & 1,590 & 34.65 \\
\hline & Southern & 2,139 & 46.61 \\
\hline \multirow[t]{2}{*}{ Religion } & Muslims & 539 & 11.81 \\
\hline & Christians ${ }^{1}$ & 4026 & 88.19 \\
\hline \multirow[t]{7}{*}{ Ethnicity } & Chewa & 1,443 & 31.44 \\
\hline & Tumbuka, Nkhonde and Tonga & 668 & 14.56 \\
\hline & Lomwe & 829 & 18.06 \\
\hline & Yao & 538 & 11.72 \\
\hline & Sena, Mang'anja, Nyanja & 394 & 8.59 \\
\hline & Ngoni & 563 & 12.27 \\
\hline & Other & 154 & 3.36 \\
\hline \multicolumn{4}{|l|}{ Socio-economic factors } \\
\hline \multirow[t]{5}{*}{ Wealth status } & Poorest & 824 & 17.96 \\
\hline & Poorer & 974 & 21.22 \\
\hline & Middle & 936 & 20.40 \\
\hline & Richer & 887 & 19.33 \\
\hline & Richest & 968 & 21.09 \\
\hline \multirow[t]{2}{*}{ Husband takes alcohol } & Yes & 1,365 & 70.25 \\
\hline & No & 3,224 & 29.73 \\
\hline \multirow[t]{2}{*}{ Education level } & No education & 605 & 13.18 \\
\hline & Primary & 2,961 & 64.52 \\
\hline
\end{tabular}

\footnotetext{
${ }^{1}$ Christians are comprised of the following denominations: catholics, Central Church of African Presbyterians (CCAP), Seventh Day Adventists, Anglican (aka Church of England) and Pentecostals.
} 


\begin{tabular}{crcc} 
& Secondary & 1,023 & 22.29 \\
Respondent currently working & No & 1,523 & 33.19 \\
& Yes & 3,066 & 66.81 \\
Polygamous marriage & Yes & 588 & 12.81 \\
& No & 4,001 & 87.19 \\
\hline
\end{tabular}

\section{Statistical Analysis}

\section{Cluster analysis}

Cluster analysis is used to extract meaningful groupings of the experience of domestic violence from the MDHS. The experience of abuse used in the survey is defined as whether the woman has ever experienced a specific act of violence from her current spouse or partner. Eighteen binary variables are used in forming clusters, each taking the form of a $0 / 1$ indicator variable where the variable takes the value 1 if the woman reports experiencing that form of domestic abuse and zero otherwise. We include three domains of domestic abuse: physical (formed using reports of the woman being: pushed, slapped, punched, kicked, strangled, threatened with a weapon, limb twisted), sexual (physically forced into sex, coerced into sex, forced to perform a sex act) and controlling behaviour (husband exhibits jealous behaviour, accused of being unfaithful, needs permission to see friends, needs permission to see family, needs to justify whereabouts, humiliated, threatened, insulted).

The major advantage of the cluster analytic approach is that it is able to extract meaningful groupings on the experience of violence. This is an advantage over techniques such as Principal Component Analysis which rely more on analyst interpretation when extracting groupings of behavior(Hair et al., 2009). The approach is conceptually analogous to other grouping techniques such as Latent Class Analysis, and has been applied in other contexts where extracting sub population groupings is of research interest from a number of different indicator variables (Amos et al., 2018). Cluster analysis is performed using hierarchical cluster analysis based on Ward's distance cluster function in Stata 13.0 for Windows (StataCorp, 2013). To decide on the number of clusters, we use a combination of indices appropriate for hierarchical clustering which indicate optimal clustering pattern Duda-Hart index (Duda \& Hart, 1973) and pseudo T statistic and dendritic analysis.

\section{Regression analysis}


Once the final cluster profile was selected, membership of a particular cluster was then used as the dependent variable in a multinomial logistic regression. A multinomial logistic regression model is appropriate because instead of running four separate regression models, separate logistic regression models for each indicator variable are estimated simultaneously, allowing for mutually exclusive response categories to be analysed without the need for overlapping reference categories (Agresti, 2019; C. J. Anderson \& Rutkowski, 2008).

The model takes the form of equation 1

$$
\begin{gathered}
\ln \left(\frac{\pi^{S}}{\pi^{S=0}}\right)=\boldsymbol{\beta}^{\prime} \boldsymbol{x} \\
S=0 \ldots S
\end{gathered}
$$

In equation 1 the probability of belonging to cluster $s$ is denoted as $\pi^{S}$ where there are $S$ clusters. The probability of belonging to cluster $S$ is modelled as a logit function of a combination of a vector of coefficients $\boldsymbol{\beta}$ and associated predictor variables in the vector $x$. $S-1$ logits are estimated and the baseline cluster $s=0$ is omitted to identify the model. (C. J. Anderson \& Rutkowski, 2008). Estimated coefficients $\boldsymbol{\beta}$ are produced on a logit scale, with values above 0 indicating an increase in the probability of belonging to cluster $s$ relative to the omitted category and those below zero indicating a decrease. To ease interpretation, we exponentiate the coefficient on to the logged odds scale, where coefficients above 1 indicate the percentage increase in the probability of being in cluster $s$ compared to the reference, whereas figures below 1 indicates the percentage reduction in the probability compared to baseline.

\section{Results}

\section{Cluster analysis}

Five distinct clusters of abuse were extracted based on a combination of fit statistics and dendritic analysis. The 5 clusters have the highest Duda-Hart index (0.897), compared to other proximate solutions (Cluster 4 has a Duda-Hart statistic of 0.036, while Cluster 6 has a DudaHart value of 0.789 ). This is confirmed by the related pseudo $\mathrm{T}$ statistic where the value for 5 clusters is minimised at 142.56, compared to larger values for 4 (44946.56) and 6 (331.13) cluster solutions. Out of the 6,379 households that responded to the domestic violence questions, data on type of abuse was available for 4,569 women. 
The profile of domestic abuse is presented in figure 2. The first cluster is termed no abuse (NA), and contains women who reported no experience of abuse on any of the response variables. This cluster comprises $25.39 \%$ of the sample. The second cluster extracted is characterised by Controlling Behaviour (CB). All women within this cluster report that they have experienced their spouse demanding knowledge of their whereabouts, but no other form of abuse is present. This cluster comprises 541 women, or $11.79 \%$ of the sample. The third cluster comprises general controlling behaviour (GCB). Women in this cluster experience high rates of jealousy from their husbands (84\%) and their husbands demand to know whereabouts (77\%), as well as lower level of accusations of being unfaithful (30\%), isolation from friends (22\%) and family (17\%). All indicators of physical abuse are low (below 5\%). This is the second largest cluster in the sample comprising 1245 women $(27.13 \%)$.

Cluster 4 comprises moderate physical and emotional abuse (MPE). Emotional abuse is common in this cluster, with high rates of jealous behaviour (60\%) and control of whereabouts (67\%). A substantial minority of women in this cluster have experienced physical abuse largely in the form of being slapped (39\%) and being forced to perform a sex act (37\%). This cluster is the largest in the sample with 1250 women (27.24\% of the sample).

Cluster 5 represents the highest overall level of abuse, and is termed the high and complete abuse (HCA). Nearly all women in this cluster have experienced some form of physical abuse, with particular high rates of being slapped (90\%), punched $(65 \%)$ and kicked $(60 \%)$. Women in this cluster also report high rates of forced sex (65\%). Controlling behaviour and emotional abuse is also common in this cluster, particularly jealous behaviour (90\%), knowledge about whereabouts $(90 \%)$ being humiliated $(55 \%)$, threatened $(65 \%)$ or insulted $(75 \%)$. This cluster comprises 288 women and is $8.46 \%$ of the sample.

Figure 2: Experience of forms of domestic abuse by form of abuse for each cluster 



\section{Multinomial logistic regression results}

Results of the multinomial regression analysis are presented in Table 2. The odds of a woman encountering a particular profile of domestic violence are presented under each column; controlling behaviour, generalised controlling behaviour, moderate physical and emotional abuse and high and complete abuse compared to the base category of No abuse. Statistically significant results ( $p$ value $<0.05$ ) are in bold.

\section{Controlling behaviour}

The odds of a woman encountering controlling behaviour were $35 \%$ lower for women aged 20 to 29 and $36 \%$ lower for those aged 30 to 39 compared to those aged 15 to 19 . Women from the Central region had $69 \%$ higher odds of experiencing controlling behaviour compared to women from the Northern region. Christian women were less likely to encounter controlling behaviour compared to Muslim women, their odds were 39\% lower than that of Muslim women. Women of Yao and Ngoni ethnicity were less likely to encounter controlling behaviour than women of Chewa ethnicity. Interestingly, more well off women were more likely to encounter controlling behaviour than the poorest $45 \%$ more likely for the poorer and middle categories and $78 \%$ more likely for those in the richest category). Similarly, women that reported to be currently working were more likely to have encountered controlling behaviour from their husbands than women that were not currently working. The highest difference in the odds of encountering controlling behaviour was 
between women whose husbands drink alcohol and those that do not. Women who reported that their husbands drink alcohol had $80 \%$ higher odds of encountering controlling behaviour compared to women who reported that their husbands do not drink alcohol.

\section{Generalised controlling behaviour}

The odds of women encountering generalised controlling behaviour were also lower for older women compared to the youngest age group (15 to 19 years). The association was only statistically significant amongst the oldest group (40 to 49 years). Women aged between 40 to 49 years had $41 \%$ lower odds of encountering generalised controlling behaviour compared to women aged 15 to 19 years. Christian women had $46 \%$ lower odds of encountering this form of domestic violence compared to Muslim women. Compared to Chewa women, the odds of encountering this form of domestic violence were $40 \%$ higher for Lomwe women, 34\% lower for Yao women and 37\% lower for Ngoni women. Women that were in the poorer group of the household wealth status variable were more likely to encounter this form of domestic violence compared to women in the poorest category; the odds were $31 \%$ higher. Women who reported that their husbands drink alcohol were twice as likely to experience this form of domestic violence compared to women who reported that their husbands do not drink alcohol. The odds of suffering generalised controlling behaviour were $31 \%$ higher for women that reported to be currently working than women that were not working and $58 \%$ higher for women in a polygynous marriage than those in a monogamous marriage.

\section{Moderate physical and emotional abuse}

There was no significant association between age, region, religion and this profile of domestic violence. A statistically significant association was obtained between this form of domestic violence and the following factors: ethnicity, education level, whether the husband drinks alcohol or not, women's working status and type of marriage. The odds of experiencing this form of domestic violence were $26 \%$ lower for Ngoni women than Chewa women, over three times higher for women who reported that their husbands drink alcohol than women who reported that their husbands do not drink alcohol, 34\% higher for women with primary education than those with no education, $36 \%$ higher for currently working women than those not working and $76 \%$ higher for women in polygynous marriage than those in a monogamous marriage.

\section{High and complete abuse}

Factors that emerged as significantly associated with high and complete abuse are age at first sex, ethnicity, household wealth status, husband's consumption of alcohol, education level, working status and marriage type. Women that reported to have had their first sex at the age 
of 18 years or more had lower odds of experiencing this form of domestic violence than women who had their first sex aged less than 14 years. The odds of experiencing this form of domestic violence were 66\% higher for Lomwe women and 68\% higher for Sena, Mang'anja, and Nyanja women than Chewa women. Women in the poorer category of the household wealth status variable had $63 \%$ higher odds of experiencing this form of domestic violence than those in the poorest category. The odds of experiencing this profile of domestic violence for women that reported that their husbands drink alcohol were nearly seven times higher than the odds for women that reported that their husbands do not drink alcohol. Women with primary education had nearly double the odds of experiencing this type of domestic violence than women with no education. The odds of experiencing this type of domestic violence were $40 \%$ higher for women that reported to be currently working than those not working and were three times higher for women in polygynous marriage than for women in monogamous marriage.

Table 2 Results of multinomial logistic regression results on type and severity of domestic violence, 2015 MDHS

\begin{tabular}{|c|c|c|c|c|}
\hline $\begin{array}{l}\text { Variables in the Model: } \\
\text { The base is No Abuse Category }\end{array}$ & $\begin{array}{l}\text { Controlling } \\
\text { behaviour }\end{array}$ & $\begin{array}{l}\text { Generalised } \\
\text { controlling } \\
\text { behaviour }\end{array}$ & $\begin{array}{l}\text { Moderate physical } \\
+ \text { emotional abuse }\end{array}$ & $\begin{array}{l}\text { High and } \\
\text { complete abuse }\end{array}$ \\
\hline \multicolumn{5}{|l|}{ Age : 15 to 19 is reference } \\
\hline Aged 20 to 29 & $0.65(0.44,0.95)$ & $0.84(0.62,1.15)$ & $0.96(0.69,1.33)$ & $1.62(0.91,2.87)$ \\
\hline Aged 30 to 39 & $0.66(0.44,0.99)$ & $0.89(0.64,1.24)$ & $1.16(0.82,1.63)$ & $1.51(0.83,2.73)$ \\
\hline Aged 40 to 49 & $0.67(0.42,1.05)$ & $0.59(0.40,0.85)$ & $0.78(0.53,1.15)$ & $1.46(0.77,2.77)$ \\
\hline \multicolumn{5}{|l|}{$\begin{array}{l}\text { Aged at first sex: } \\
\text { less than } 14 \text { years is reference }\end{array}$} \\
\hline Between 14 to 17 years & $0.99(0.56,1.50)$ & $0.80(0.59,1.09)$ & $0.80(0.59,1.09)$ & $0.83(0.54,1.28)$ \\
\hline 18 years or more & $1.23(0.79,1.91)$ & $0.78(0.56,1.08)$ & $0.80(0.58,1.12)$ & $0.61(0.38,0.98)$ \\
\hline \multicolumn{5}{|l|}{ Region: Northern is reference } \\
\hline Central region & $1.69(1.06,2.69)$ & $1.13(0.79,1.63)$ & $1.42(0.98,2.05)$ & $1.34(0.78,2.31)$ \\
\hline Southern region & $1.10(0.68,1.76)$ & $0.85(0.59,1.23)$ & $0.85(0.58,1.24)$ & $0.99(0.57,1.71)$ \\
\hline \multicolumn{5}{|l|}{ Religion: reference is Muslims } \\
\hline Christians & $0.61(0.39,0.94)$ & $0.54(0.38,0.76)$ & $1.02(0.70,1.49)$ & $1.04(0.58,1.86)$ \\
\hline \multicolumn{5}{|l|}{ Ethnicity: reference is Chewa } \\
\hline Tumbuka, Nkhonde and Tonga & $1.00(0.61,1.64)$ & $1.19(0.81,1.75)$ & $1.37(0.93,2.01)$ & $1.20(0.67,2.13)$ \\
\hline Lomwe & $1.40(0.97,2.04)$ & $1.40(1.04,1.88)$ & $1.25(0.92,1.70)$ & $1.66(1.06,2.59)$ \\
\hline Yao & $0.52(0.32,0.85)$ & $0.66(0.46,0.96)$ & $0.75(0.51,1.12)$ & $0.86(0.47,1.59)$ \\
\hline Sena, Mang'anja and Nyanja & $1.41(0.91,2.16)$ & $0.93(0.65,1.34)$ & $1.27(0.89,1.81)$ & $1.68(1.01,2.81)$ \\
\hline Ngoni & $0.69(0.48,0.99)$ & $0.63(0.47,0.84)$ & $0.74(0.56,0.99)$ & $0.95(0.63,1.44)$ \\
\hline Other & $1.60(0.81,3.17)$ & $1.09(0.62,1.92)$ & $1.11(0.62,1.97)$ & $1.60(0.74,3.49)$ \\
\hline \multicolumn{5}{|l|}{$\begin{array}{l}\text { Household wealth status: } \\
\text { reference is Poorest }\end{array}$} \\
\hline Poorer & $1.45(1.02,2.06)$ & 1.31(1.01,1.70) & $1.22(0.94,1.60)$ & 1.63(1.11,2.38) \\
\hline Middle & $1.45(1.02,2.06)$ & $1.04(0.79,1.36)$ & $1.22(0.94,1.59)$ & $1.21(0.81,1.80)$ \\
\hline
\end{tabular}


Rich

Richest

Alcohol intake: reference is

Husband does not take alcohol

Husband takes alcohol

Education level: reference is

No education

Primary education

Secondary education or higher

Working status: reference is

Respondent currently not working

Respondent currently working

Type of marriage: reference is

Monogamous marriage

Polygamous marriage
$1.21(0.92,1.60)$

$1.15(0.87,1.51)$

$1.33(0.99,1.77)$

$1.21(0.90,1.63)$

$1.42(0.95,2.13)$

1.78(1.22,2.60)

$1.80(1.39,2.33)$

2.00(1.62,2.46)

$3.30(2.70,4.03)$

6.91(5.30,9.00)

$1.10(0.79,1.54)$

$1.12(0.87,1.44)$

$1.34(1.03,1.74)$

$1.95(1.29,2.94)$

$1.11(0.74,1.67)$

$1.05(0.76,1.45)$

$0.81(0.58,1.13)$

$1.21(0.72,2.03)$

Note: Coefficients are relative risk ratios compared to being members of the no abuse cluster

$1.25(1.00,1.56)$

1.31(1.10,1.56)

1.36(1.14,1.62)

$1.40(1.08,1.82)$

\section{Discussion}

This paper examined patterns and correlates of domestic violence against married women in Malawi using cluster analysis and multinomial logistic regression. The study explored violence against women across women of different socio-economic status, education levels, geographical contexts and ethnic background. Five distinct and meaningful clusters/levels of abuse were extracted from the most recent nationally representative data; no experience of abuse, controlling behaviour, generalised controlling behaviour, moderate physical and emotional abuse and high and complete abuse.

Alcohol consumption, ethnicity and women's working status were significantly associated with all levels of abuse. The crucial role of alcohol consumption in various types of domestic violence has been reported in numerous pieces of literature around the globe (Brecklin \& Ullman, 2002; Gilchrist et al., 2003; McKinney et al., 2009). Alcohol consumption reduces cognitive function, reduces self-control and makes individuals less able to negotiate a nonviolent resolution to arguments (Bernardin, 2014; Kim et al., 2016; Room et al., 2005). On the other hand, experiencing violence can lead to alcohol abuse whereby individuals may resort to alcohol abuse as a copying mechanism(Wingood et al., 2000) but the relationship between alcohol use and intimate partner violence may at times be moderated by socioeconomic status (Greene et al., 2017). 
We learn from this study that ethnicity is an important geographical factor that is associated with domestic violence in Malawi. Compared to the Chewa, the Ngonis have lower odds of controlling or physically abusing their wives, while the Lomwe, Senas, Mang'anja and Nyanjas have higher odds of physically abusing their women. Women from Central region have significantly higher odds of experiencing controlling behaviour compared to women from northern region. The role of ecological context in influencing behavioural practices/customs was corroborated in a Malawian study that reported higher levels of stunting among children from matrilineal communities than those from patrilineal communities(Chikhungu et al., 2014). It has been reported that the likelihood of divorce is higher in matrilineal than patrilineal communities and that polygyny is more common in patrilineal societies than matrilineal societies (Arnado, 2004; Berge et al., 2013; Takyi \& Gyimah, 2007).The Chewa, Lomwe and Mang'anja are matrilineal, the Sena are patrilineal but the Ngonis and Nyanja can either be patrilineal or matrilineal depending on location.

Women's working status was also a popular factor, emerging significant in all four clusters. It is ironic however that although women's employment is an important avenue for increased gender equality, the finding from this study aligns with numerous studies that have reported that working women are more likely to encounter domestic violence than their non-working counterparts in India and sub Saharan Africa (Ahinkorah et al., 2018; Dalal, 2011; Sohini, 2016). Such a finding is not congruent with the feminist theory (Gelles, 2005) but supports the resource theory (K. L. Anderson, 1997). It has been argued that the relationship between women's working status and intimate partner violence may be influenced by whether the partner/husband believes in traditional ideologies of the role of men and women or not (Atkinson et al., 2005). Such an argument is in congruent with the resources theory on domestic violence which presupposes that family members with more resources traditionally command higher power and assure obedience and compliance while those with less resources use violence to maintain power (K. L. Anderson, 1997; Pallikadavath \& Bradley, 2018; Warner et al., 1986). But on the other hand, studies that have controlled for endogeneity when modelling the association between intimate partner violence and women's working status have not found a significant association between women's working status and domestic violence, indicating that women's working status does not necessarily lead to domestic violence (Lenze \& Klasen, 2017).

Type of marriage (whether polygynous or monogamous) also emerged as an important factor in three out of the four clusters; generalised controlling behaviour, moderate physical and 
emotional behaviour and high and complete abuse. The association was strongest for high and complete abuse and lowest in the generalised controlling behaviour. In Malawi, polygyny is common in the Northern region where bride price is practised and lineage system is patrilineal. Bride price is the payment made by the groom's family to the bride's family during marriage. It has been indicated that bride price reduces women's status to that of a possession (Gray, 1960). Historically polygyny has been linked to limitation of women's access to land, inheritance and sources of formalised power (Goody, 1973; White \& Burton, 1988). Women in polygynous unions are therefore less likely to have a more equal relationship with their partners compared to women in monogamous unions(McCloskey et al., 2005). Higher levels of domestic violence in polygynous than monogamous marriages have been reported in Malawi (Bisika, 2008) but a study in Mozambique suggests that senior wives tend to suffer more violence than junior wives and that the level of violence amongst junior wives in polygynous marriages may not significantly differ from women in monogamous marriages or unions(Jansen \& Agadjarian, 2016).

Age of the married woman and religion emerged significant in the controlling behaviour and generalised controlled behaviour clusters only. Unsurprisingly the findings indicate that younger women are more likely to be controlled than older women. With nearly $50 \%$ of girls marrying before adulthood, much higher than the figure for boys, estimated at $8 \%$, most women should be married to older men (NSO-Malawi \& ICF_International, 2017). A strong association has been established between women's age and domestic violence in a global study whereby the majority of women reported to have experienced violence in the first three years of married life, such that the relatively younger women tend to be more affected by violence than older women(Peterman et al., 2015). Similar to the findings of this study, age was not an important factor in physical violence in a sub Saharan study (Andersson et al., 2007).

The finding that Muslim women are more likely to experience controlling behaviour than Christian women may be explained by Islamic teachings that approve control and physical punishment of rebellious wives. Verse 34 of Surah An Nisa states "As to those women on whose part you fear disloyalty and ill-conduct, admonish them (first), (next) do not share beds and last beat (tap) them lightly; but if they return to obedience, seek not against them means of annoyance : for Allah is Most High, Great (above you all)"(Islam.org, 2015). Acceptance and obedience on the part of the wives may contribute to prevention of physical violence. Religion is a major influence of gender and social roles and behaviour. In Malawi, religious institutions do not recognise marital rape and signing a marriage contract is 
understood as consent to sex throughout married life(Inglehart \& Norris, 2003; Kanyongolo \& Malunga, 2011).

Household wealth status turned out to be a significant predictor of domestic violence in the generalised controlling behaviour and the high and complete abuse clusters, consistent with findings from a study in 18 sub Saharan African countries (Ahinkorah et al., 2018). Interestingly the direction of the relationship between household wealth and domestic violence varies from one place to another(Bamiwuye \& Odimegwu, 2014). In a 2014 sub Saharan Africa study on spousal violence, non-poor women from Zambia and Mozambique were more likely to experience violence than the poorer similar to the findings of this study, but in Zimbabwe and Kenya the likelihood of encountering violence was higher for poor women than the richer. On a similar note, this study found that women with primary education were more likely to encounter domestic violence than women with no education. These findings concur with reports that richest women and those with formal education in Burkina Faso have shown a higher likelihood to face psychological pressure from their partners(Pambe' et al., 2013). The behaviour of wealth status and education variables appear to suggest that socio-economic status just like woman's working status may not have a causative relationship with domestic violence in Malawi. Caution should be taken to interpret the results as associations and not causations because cross sectional data was used and we did not control for endogeneity.

\section{Conclusion and Policy Recommendations}

Alcohol consumption, ethnicity and women's working status were consistently associated with all levels of abuse. Age of the married women and religion were only significantly associated with controlling behaviour and generalised controlling behaviour. Alcohol consumption, women's working status and polygyny showed a dose response relationship; the difference in the odds of encountering domestic violence was much higher in the moderate physical and emotional abuse and the high and complete abuse profiles than in the controlling and generalised controlling behaviour, suggesting that these factors may be key to tackling domestic violence in Malawi. The Malawi Government and development partners should consider designing policies and programmes that tackle excessive beer drinking, promotion of the acceptance that women can be breadwinners and discouraging the practice of polygyny to curb violence against women in Malawi. Future studies could use ethnographic methods to explore further why some ethnicities show higher levels of domestic violence against married women than others. 


\section{References}

Agresti, A. (2019). An introduction to categorical data analysis: John Wiley and sons.

Ahinkorah, B. O., Dickson, K. S., \& Seidu, A.-A. (2018). Women decision-making capacity and intimate partner violence among women in sub-Saharan Africa. Archives of Public Health, 76(5). doi: http://doi.org/10.1186/s13690-018-0253-9

Alio, A. P., Clayton, H. B., Garba, M., Mbah, A. K., Daley, E., \& Salihu, H. M. (2011). Spousal concordance in attitudes toward violence and reported physical abuse in African couples. $J$ Interpers Violence, 26(14), 2790-2810. doi: 10.1177/0886260510390951

Amos, M., Hossain, A., Mahmood, S. S., Mohammed, N. M., Mia, N., Rana, M. S., . . Pallikadavath, S. (2018) Do young mothers get the care they need? Mapping age disparities across the maternal continuum of care using a holistic clustering technique: Preliminary findings University of Portsmouth.

Anderson, C. J., \& Rutkowski, L. (2008). Multimomial Logistic Regression. In J. Osborne (Ed.), Best practices in Quantitative Methods. Online: Sage Publications.

Anderson, K. L. (1997). Gender, Status, and Domestic Violence: An Integration of Feminist and Family Violence Approaches. Journal of Marriage and Family, 59(3), 655-669. doi: 10.2307/353952

Andersson, N., Ho-Foster, A., Mitchell, S., Scheepers, E., \& Goldstein, S. (2007). Risk factors for domestic physical violence: national cross-sectional household surveys in eight southern African countries. BMC Womens Health, 7, 11. doi: 10.1186/1472-6874-7-11

Arnado, C. (2004). Ethnicity and Marriage Patterns in Mozambique. African Population Studies, 19(1), 143-164.

Atkinson, M. P., Greenstein, T. N., \& Lang, M. M. (2005). For Women, Breadwinning Can Be Dangerous: Gendered Resource Theory and Wife Abuse. Journal of Marriage and Family, 67(5), 1137-1148.

Bamiwuye, S. O., \& Odimegwu, C. (2014). Spousal violence in sub-Saharan Africa: does household poverty-wealth matter? Reprod Health, 11, 45. doi: 10.1186/1742-4755-11-45

Berge, E., Kambewa, D., Munthali, A., \& Wiig, H. (2013). Lineage and Land Reforms in Malawi: Do Matrilineal and Patrilineal Landholding Systems Represent a Problem for Land Reforms in Malawi? Centre for Land Tenure Studies Working Paper 09/13, Nowergian University of Life Sciences, Aas, Norway.

Bernardin, F., Maheut-Bosser, A., \& Paille, F. . (2014). Cognitive Impairments in Alcohol-Dependent Subjects. Frontiers in Psychiatry, 5(78). doi: http://doi.org/10.3389/fpsyt.2014.00078 
Bisika, T. (2008). Do social and cultural factors perpetuate gender based violence in Malawi. Gender and Behaviour, 6(2), 1884-1896.

Brecklin, L. R., \& Ullman, S. E. (2002). The roles of victim and offender alcohol use in sexual assaults: results from the National Violence Against Women Survey. J Stud Alcohol, 63(1), 57-63.

Carson, B. E. (1984). Causes and maintenance of Domestic Violence: an ecological analysis. Social Service Review, 58(4), 569-587.

Chikhungu, L. C., Madise, N. J., \& Padmadas, S. S. (2014). How important are community characteristics in influencing children's nutritional status? Evidence from Malawi populationbased household and community surveys. Health \& Place, 30, 187-195.

Dalal, K. (2011). Does economic empowerment protect women from intimate partner violence? J Inj Violence Res, 3(1), 35-44. doi: 10.5249/jivr.v3i1.76

Dobash, R. E., \& Dobash, R. (1979). Violence against wives: a case against the patriarchy. New York: Free Press.

Duda, R. O., \& Hart, P. E. (1973). Pattern Classification and Scene Analysis. New York: Wiley.

Fageeh, W. M. K. (2014). Factors associated with domestic violence: a cross-sectional survey among women in Jeddah, Saudi Arabia. BMJ Open, 4(2), e004242. doi: 10.1136/bmjopen-2013004242

Fan, A. Z., Liu, J., Kress, H., Gupta, S., Shawa, M., Wadonda-Kabondo, N., \& Mercy, J. (2017). Applying Structural Equation Modeling to Measure Violence Exposure and Its Impact on Mental Health: Malawi Violence Against Children and Young Women Survey, 2013. J Interpers Violence, 886260517741214. doi: 10.1177/0886260517741214

Gelles, R. J. (2005). Through a sociological lens: social structure and family violence. In R. J. Gelles \& D. R. Loseke (Eds.), Current controversies of family violence: Sage.

Gilchrist, E., Johnson, R., Takriti, R., Westo, S., Beech, A., \& Kebbell, M. (2003). Domestic violence offenders: characteristics and offending related needs. London: UK Home Office.

Goody, J. (1973). The character of kinship. Cambridge: Canbridge University Press.

Gray, R. F. (1960). Sonjo Bride-Price and the Question of African "Wife Purchase". American Anthropologist, 62(1), 34-57.

Greene, M. C., Kane, J. C., \& Tol, W. A. (2017). Alcohol use and intimate partner violence among women and their partners in sub-Saharan Africa. Glob Ment Health (Camb), 4, e13. doi: 10.1017/gmh.2017.9

Hair, J. F., Black, W. C., Babin, B. J., \& Anderson, R. E. (2009). Multivariate Data Analysis.

Hyde-Nolan, M. E., \& Juliao, T. (2011). Theoretical basis for family violence. In F. S. Ross \& S. Sarina (Eds.), Family violence: What health care providers need to know: Jones and Bartlett.

Inglehart, R., \& Norris, P. (2003). Rising tide: Gender equality and cultural change around the world. Cambridge University Press. Cambridge University Press.

Islam.org, W. (2015). What Islam says about Domestic Violence. Retrieved 29th August, 2018, 2018, from https://www.whyislam.org/social-issues/islam-domestic-violence/

Jansen, N. A., \& Agadjarian, V. (2016). Polygyny and intimate partner violence in a rural sub Saharan setting. Paper presented at the Population Association of America.

Jewkes, R. K. (2002). Preventing domestic violence: most women wel- come inquiries, but doctors and nurses rarely ask about it. Editorial. BMJ, 324(7332).

Kaminaga, A. S. (2017). Acceptance of Intimate Partner Violence in Rural Malawi: An Empirical Analysis on the Impacts of Lineage and AIDS Conversation Networks. J Interpers Violence, O(0), 0886260517703375. doi: 10.1177/0886260517703375

Kanyongolo, N. R., \& Malunga, B. (2011). The treatment of consent in sexual assault law in Malawi.

Kim, S., Kim, Y., \& Park, S. M. (2016). Association between alcohol drinking behaviour and cognitive function: results from a nationwide longitudinal study of South Korea. BMJ Open, 6(4). doi: 10.1136/bmjopen-2015-010494

Lenze, J., \& Klasen, S. (2017). Does Women's Labor Force Participation Reduce Domestic Violence? Evidence from Jordan. Feminist Economics, 23(1), 1-29. 
McCloskey, L. A., Williams, C., \& Larsen, U. (2005). Gender inequality and intimate partner violence among women in Moshi, Tanzania. Int Fam Plan Perspect, 31(3), 124-130. doi: 10.1363/ifpp.31.124.05

McKinney, C. M., Caetano, R., Harris, T. R., \& Ebama, M. S. (2009). Alcohol availability and intimate partner violence among US couples. Alcohol Clin Exp Res, 33(1), 169-176. doi: 10.1111/j.1530-0277.2008.00825.x

Mellish, M., Settergren, S., \& Sapuwa, H. (2015). Gender-based Violence in Malawi: A Literature Review to Inform the National Response. Washington DC: Futures Group, Health Policy Project.

NSO-Malawi. (2012). Integrated Household Survey: Household Socio-economic characteristics report. Zomba, Malawi: National Statistical Office of Malawi.

NSO-Malawi, \& DHS-Program. (2017). Malawi Demographic and Health Survey Report 2015-2016. Zomba, Malawi and Rockville, Maryland USA: NSO and ICF.

NSO-Malawi, \& ICF_International. (2017). Malawi Demographic and Health Survey Report 20152016. Zomba, Malawi and Rockville, Maryland USA: NSO and ICF.

Pallikadavath, S., \& Bradley, T. (2018). Dowry, 'Dowry autonomy' And domestic violence among young married women in India. J Biosoc Sci, 1-21. doi: 10.1017/s0021932018000226

Pambe', M. W., Gnoumou, B., \& Kabore', I. (2013). Relationship between women's soci-economic status and empowerment in Burkina Faso: A focus on participation in decision making and ecperience of domestic violence: USAID.

Peterman, A., Bleck, J., \& Palermo, T. (2015). Age and Intimate Partner Violence: An Analysis of Global Trends Among Women Experiencing Victimization in 30 Developing Countries. Journal of Adolescent Health, 57(6), 624-630. doi: https://doi.org/10.1016/j.jadohealth.2015.08.008

Rasoulian, M., Habib, S., Bolhari, J., Hakim Shooshtari, M., Nojomi, M., \& Abedi, S. (2014). Risk Factors of Domestic Violence in Iran. Journal of Environmental and Public Health, 2014, 9. doi: $10.1155 / 2014 / 352346$

Renzetti, C. M., Edleson, J. L., \& Bergen, R. K. (2001). Sourcebook on violnce against women: Sage.

Room, R., Babor, T., \& Rehm, J. (2005). Alcohol and public health. Lancet, 365(9458), 519-530. doi: 10.1016/s0140-6736(05)17870-2

Sapkota, D., Bhattarai, S., Baral, D., \& Pokharel, P. K. (2016). Domestic violence and its associated factors among married women of a village development committee of rural Nepal. BMC research notes,, 9(178). doi: doi:10.1186/s13104-016-1986-6

Sharma, B. R. (1997). Women, marriage,family, violence and divorce. Jaipur: Mangal Deep.

Sohini, P. (2016). Wmone's Labour Force Participation and Domestic Violence. Journal of South Asian Development, 11(2), 224-250.

StataCorp. (2013). Stata Statistical Software: Release 13. StataCorp LP: College Station, TX.

Strauss, M. A., Gelles, R. J., \& Steinmetz, S. K. (1980). Behind closed doors: violence in the American family. Garden City New York: Double Day.

Takyi, B. K., \& Gyimah, S. O. (2007). Matrilineal Family Ties and Marital Dissolution in Ghana. Journal of Family Issues, 28(682).

Telalagić, S. (2012). Domestic Production as a Source of Marital Power: Theory and Evidence from Malawi. Cambridge Working Papers in Economics CWPE 1243. Cambridge, UK. Cambridge, UK.

United-Nations. (2018). Sustainable development goal 5: Achieve gender equality and empower all women and girls. Sustainable development knowledge platform. Retrieved 24th July 2018, 2018, from https://sustainabledevelopment.un.org/sdg5

Warner, R. L., Lee, G. R., \& Lee, J. (1986). Social Organization, Spousal Resources, and Marital Power: A Cross-Cultural Study. Journal of Marriage and Family, 48(1), 121-128. doi: 10.2307/352235

White, D. R., \& Burton, M. L. (1988). Causes of polgyny; ecology, economy,kinship and warfare. American Anthropologist, 90, 871-887. 
WHO. (2017). WHO Fact Sheet: Violence against women. 2018, from http://www.who.int/newsroom/fact-sheets/detail/violence-against-women

WHO. (2018). The ecological framework. The global campaign for violence prevention. Retrieved 28th July, 2018, from http://www.who.int/violenceprevention/approach/ecology/en/

Wingood, G. M., DiClemente, R. J., \& Raj, A. (2000). Adverse consequences of intimate partner abuse among women in non-urban domestic violence shelters. Am J Prev Med, 19(4), 270-275. 